\title{
La tradición de los amados de Dios en Qumrán. Antecedentes para un estudio del discípulo amado en el cuarto evangelio
}

\author{
César Carbullanca Núñez. \\ UNIVERSIDAD CATÓLICA DEL MAULE \\ TALCA, CHILE
}

\subsection{Introducción}

La figura del discípulo amado ${ }^{1}$ en el cuarto evangelio resulta enigmática y sigue provocando mucha literatura a los estudiosos del cuarto evangelio. El presente artículo desarrolla la hipótesis de que la figura del discípulo amado según nos la presenta el cuarto evangelio se comprende mejor a partir de la tradición de los amados de Dios tal como se desarrolla en el judaísmo tardío, en los grupos apocalípticos y en Qumrán alrededor de la primera centuria a. C. Para lo cual, las reflexiones que siguen desarrollan en primer lugar, el origen apocalíptico de dicha figura ligado a tradiciones norteñas o samaritanas; en segundo lugar, mostrará que tal designación contiene tanto la idea de una exaltación o glorificación como la del sufrimiento del amado a causa del servicio a Dios. En tercer lugar, muestra que éste responde a un modelo profético de enviado y que por consiguiente, tanto la cristología del enviado como la figura del discípulo amado pertenecen a una misma matriz ideológica y no a dos etapas o fases y por consiguiente a dos teologías distintas en la historia de la redacción del cuarto evangelio ${ }^{2}$.

1 El artículo es parte del proyecto Fondecyt de iniciación 11085038: El profeta escatológico: estudio de los orígenes de la cristología del cuarto evangelio; I. GRUENWALD, Apocalyptic and Merkabah Mysticism (Leiden 1980) 29-72; la crítica a T. Eskola en P. GoODER, Review: Messiah and the Throne Jewish Merkbah Misticism and Early Exaltation discourse by Timo Eskola (WUNT 2, 142) (Tübingen 2001), JTS 54 (2001) 209-212.

2 Me refiero a la teoría de los estratos cf. L. MARTYN, The History \& Theology in the fourth Gospel (New York 1968); revisada: Nashville 1979; una visión general en R. KYSAR, «The Gospel of John in current research», Vol 9 ReStRe (1983) 4, 314-321; R. SCHNACKENBURG, El evangelio según San Juan (Barcelona, 1987), 13-19.95-108; J. Ashton, 
La tradición del amado del rey o amado de Yahvéh es concomitante con la categoría del emisario ya estudiada por J. Ashton ${ }^{3}$, J. Bühner y por nosotros en un artículo reciente ${ }^{4}$, la cual es el presupuesto para comprender el origen de la cristología joánica. Estos autores han mostrado que el modelo angelomórfico que encontramos en la apocalíptica judía, en Qumrán y en escritos cristianos se describe al enviado como el amado de Yabvéb el cual luego de realizar su misión es exaltado ${ }^{5}$. Tanto en la tradición sinóptica como en el evangelio de Juan encontramos reiteradas veces la denominación el amado para referirse tanto al Hijo como al discípulo amado ${ }^{6}$; de la misma manera encontramos el tema de la glorificación del Hijo o su exaltación en los cielos entendida ésta mediante muerte en cruz o por una reivindicación al final de los tiempos. El motivo del amado refleja un oficio profético de un mensajero, ángel, que tiene por cometido anunciar el juicio en el mundo. Pareciera entonces que el desarrollo del tema del amado en un contexto apocalíptico, su posible relación con tradiciones norteñas o samaritanas, como el tema del envío, exaltación y sufrimiento, así como su carácter profético, establecen múltiples contactos con el cuarto evangelio.

En nuestro artículo expondremos primeramente los antecedentes bíblicos de dicho motivo, en un segundo momento estudiaremos de acuerdo con un criterio lingüístico, los antecedentes que nos entregan los relatos de Qumrán sobre la figura del amado de Dios, específicamente (4Q377 f.1 recto col. II, 5-12; CD-A col.III, 1-21 (=4Q269, 2); 4Q491 fr. 1; 4Q427; 4Q213 4QAramaic Levia; y 4Q522 fr. 9 col. II) que hablan de la tradición del amado del rey, que es exaltado en los cielos y que posee funciones escatológicas, luego, presentamos algunos contactos con la figura

«Introduction. The Problem of John, 7-25», en J. Ashton (ed), Interpretation of John, (Edinburgh ${ }^{2} 1997$; H. J. KuHN, Christologie und Wunder. Untersuchungen zu Joh 1, 35-51 (Regensburg, 1988) 68.

3 J. Ashton, Understanding the Fourth Gospel, (Oxford 1991); J. L. Staley, «Ashton, John Studying John: approaches to the Fourth Gospel» RBL 26 (2000), 1-3; J. PAinter, «The Quest for the Messiah. The History, Literature and Theology of the Johannine Community» (Nashville $\left.{ }^{2} 1993\right)$ 50-51.

4 «Orígenes de la cristología del cuarto evangelio. Un estudio a partir de la tradición de 11QMelquisedec», Teología y vida, vol. L (2009) N³, 567-597.

5 Cf. J. Roloff, «Der Johanneische Lieblingsjünger und der Lehrer der Gerechtigkeit», NTS, XV (1968-1969), 132-134.

6 «El discípulo amado: clave hermenéutica de la cristología joánica», Revista Xaveriana, $\mathrm{N}^{\circ} 166$ (2008) 58, 411-437. 
del discípulo amado en el cuarto evangelio y finalmente exponemos las conclusiones de nuestra investigación.

\subsection{Antecedentes en el mundo bíblico}

Para el ideal clásico, los filósofos son los verdaderos amigos de los dioses, ocurre otro tanto en el mundo judío, donde los patriarcas como Abrahán, Jacob o profetas como Moisés o Samuel son llamados amigos de Dios. Las expresiones que se utilizan para describir esta función son varias: la palabra רע, compañero, amigo, es traducida por la LXX indistintamente por

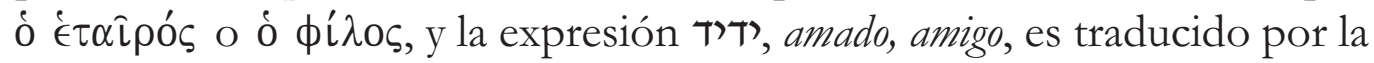

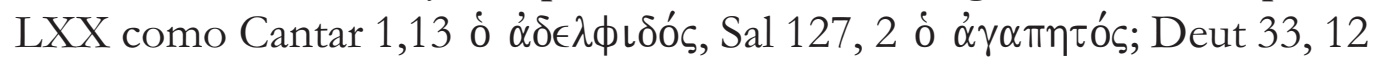

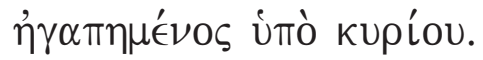

La tradición del amigo del rey se remonta a la época del pre-exilio, durante esta fase de la historia de Israel se atestigua en diferentes textos la descripción de funciones propias de las cortes monárquicas del antiguo oriente. La estructura monárquica contempla diversas funciones: secretarios, ministros, generales en jefes y la existencia de amigos del rey (ver 2 Sam 13, 3; 15, 37; 1 Re 4, 5; 1 Cr 27, 33). Estos últimos fueron muy posiblemente consejeros en cuestiones dedicadas para la marcha del reino, así como la realización de funciones particulares ordenadas por los monarcas. Los amigos del rey ejercen distintas funciones en la corte real, entre ellos hay ministros, sacerdotes, generales en jefe, servidores del monarca o simplemente amigos bien situados en la esfera del poder. Por ejemplo, en el texto de 2 Sa 15, 37 se menciona a un amigo de David (2 Sa

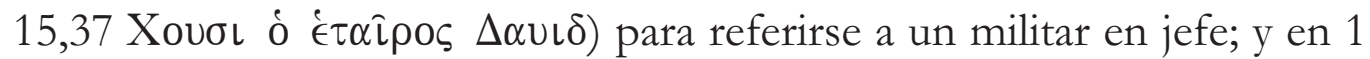

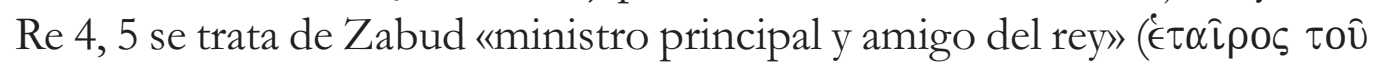
$\beta \alpha \sigma \iota \lambda \epsilon^{\prime}(\omega \varsigma)$. En 1 Cr 27, 33 muestra a Husai amigo de David es el que reconoce al ungido de Israel y aconseja a éste en las decisiones acerca de su reino (2Sa 17, 1s). En el texto de 2 Sa 12, 24-25 se menciona a Salomón amado de Yabvéh, cuyo nombre es דידיה, es decir amado de Dios. A éste la LXX 1Cr

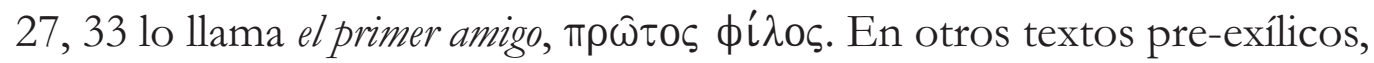
como Deut 33,10, aparece la bendición de Moisés a Benjamín que es expresada en términos que se relacionan con la figura del amado del rey (ver

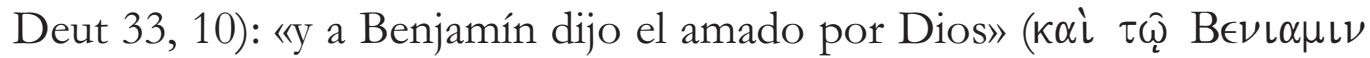

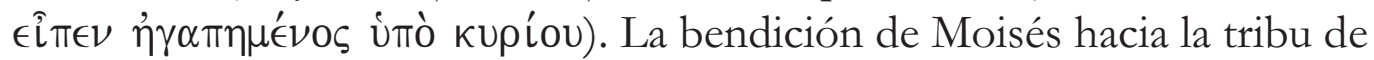
Benjamín es dada como predilección en continuidad con la bendición de Jacob a Benjamín. El patriarca es comprendido como un ser que otorga una bendición al amado. Esta característica la volveremos a encontrar en 
el cuarto evangelio, el profeta que es amado por Dios a su vez también ama con predilección a uno de sus discípulos. En relación directa con nuestro tema es sobre todo en el libro del Éxodo donde se menciona a Moisés como amigo de Dios Ex 33, 11 «Y hablaba Yahvé a Moisés cara a

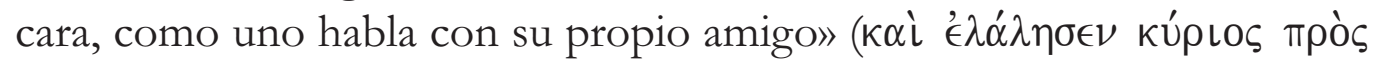

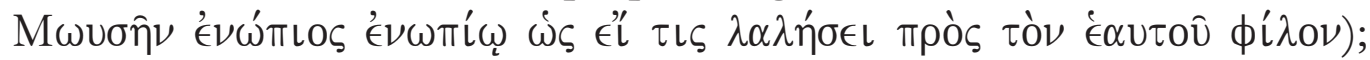

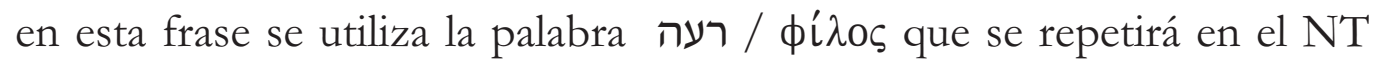
para describir a los cristianos (ver 3 Jn 15). Estos textos muestran distintas facetas de esta figura. Por un lado, el amigo del rey representa un cargo religioso-político que recae en alguien que es de entera confianza del monarca y que comparte el consejo del rey en las cuestiones que atañen al gobierno del reinado. Por otra parte, el amado del rey guarda relación con la herencia que se hace acreedor el amado por pura benevolencia del rey. Los predilectos son así vinculados a una misión que consiste en extender el dominio del rey en el tiempo.

Volviendo al texto de Ex 33, 22-23, la denominación de Moisés como

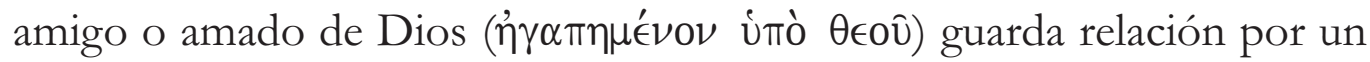
lado con la participación de Moisés en los decretos de Yahvéh sobre su pueblo. Moisés comparte los misterios de Dios en la nube y por otro lado se vincula al papel profético de Moisés en cuanto éste transmite fielmente las palabras escuchadas a Dios. Es significativo para nosotros que en estas tradiciones del éxodo encontramos las mismas características que encontraremos en las tradiciones enóquicas en torno a subrayar por un lado la trascendencia de Yahvéh y la imposibilidad para el ser humano de ver a Dios; nadie puede ver el rostro de Yahvéh, así en el texto de Ex 33, 20 23 se subraya la imposibilidad de ver el rostro de Dios y seguir vivo, o de que el conocimiento de Moisés fue imperfecto ya que éste no contempló la faz de Yahvéh sino sólo su espalda, sin embargo, prevaleció la idea de que Moisés había visto cara a cara a Dios y había tenido participación en la gloria de Yahvéh (ver Eclo 45, 1-5; Mc 9, 4-11). Esto queda ya de manifiesto en la reflexión que realiza la tradición presente en Ex 34, 2. 29, donde apunta que Moisés no sólo vio el rostro de Yahvéh, sino que su propio rostro quedó transformado al ver la gloría de Dios. Por tanto debemos ver en esta versión de Ex 33, 20-23 una revisión que refleja dos aspectos: la trascendencia de Yahvéh y no obstante esta distancia entre el hombre y Dios, la fundamentación según Ex 34, 2s de la transformación del justo en luz. 
A la vuelta del destierro, los textos de LXX Odas 7, 35; 10, 7; Dn 3, 52; Cro 20, 7 e Is 5,1; 41, 8; 51, 2 mencionan a Abraham como amado o amigo de Dios: «Dios nuestro, ¿no expulsaste tú a los habitantes de esta tierra delante de tu pueblo Israel, y la diste a la descendencia de tu amigo

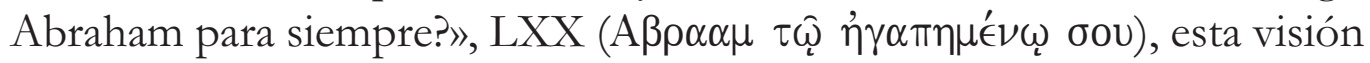
es recogida en Sant 2, 23, que le llama a Abraham amigo de Dios por

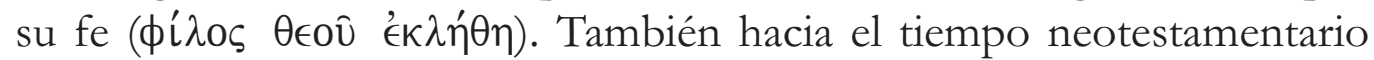

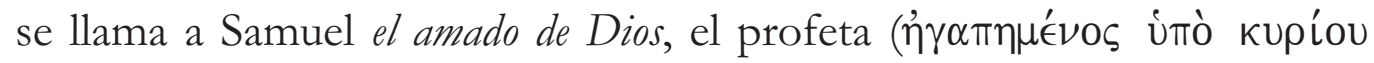

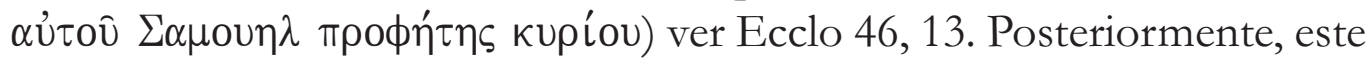
esquema será aplicado a la corte celestial en donde Dios como monarca posee para su servicio de un grupo de ministros y amigos que aconsejan y realizan los decretos sobre los hombres. En las tradiciones apocalípticas posteriores al destierro encontramos este esquema aplicado a la corte celestial, por ejemplo, lo encontramos en Zac 13, 7 donde se habla de un personaje llamado el amigo de su compañia (גבר אמיתי). En este mismo contexto, un personaje que aparece mencionado es el «otro», o «el otro ángel», esta denominación es mencionada en 1En 89, 14.17. 22 (ver Ez 9, 2) para señalar al escriba o secretario que escribe en el libro las acciones de los malos pastores, a veces entendido como Enoch (ver Jub 4, 23; 22, 25-23,7), en otros textos, parece designar a un ángel (ver En 87, 2). En esta época posterior al destierro encontramos la figura de Moisés trasparentada en los textos del déutero-Isaías, quien menciona la figura de Israel como siervo de Yahvéh ${ }^{7}$. En la reflexión del deutero-isaías aparece reiteradamente la idea que Israel es amado por Dios, así por ejemplo en Is 41, 8; 44, 2 43, 3; Os 11, 1; Israel es el siervo de Dios, que es amado por él

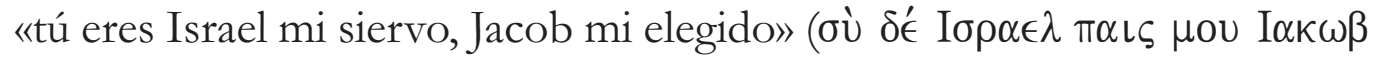

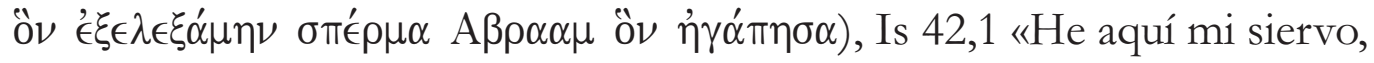

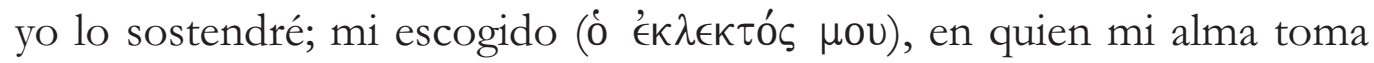
contentamiento: he puesto sobre él mi espíritu, dará juicio a las gentes».

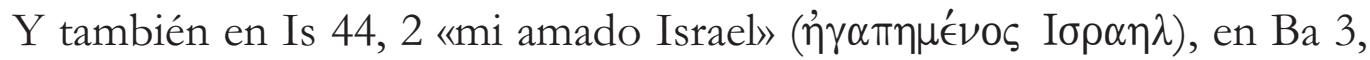

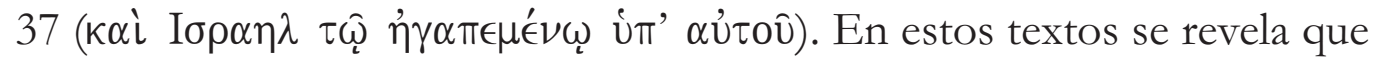
la amistad es referida a los profetas y siervos de Dios, y es comprendida como una relación en la cual se compromete la persona completa en un destino común, por lo tanto se trata de una comunión de vida y misión, ambos aspectos no están desconectados el uno del otro ni son entendidos en términos independientes. Es posible que en algunos casos como Moisés o Elías la tradición viera unido a este destino común rasgos sufrientes

Cf. G. von RaD, Teología del Antiguo Testamento II (Salamanca 1982) 323-325. 
como los que encontramos en Jeremías, el Justo del texto de Sb 4-6 o del déutero-Isaías 52-53, quien señala que Israel es siervo de Dios, amado y tiene por misión ser «luz de las naciones».

Resumiendo, podemos decir que en esta tradición se vinculan dos aspectos esenciales, por un lado es el tema de la participación en la intimidad con Dios, la cual se expresa tanto por una particular elección o regalo de parte de Dios y por otra, aparece en relación con el concepto de envío el cual es encomendado al profeta. El amigo es el profeta, el ángel que participa del consejo divino ante el trono celeste y que representa a Dios en su nombre, él es su representante en la tierra para realizar las señales escatológicas y dar el mensaje de Dios.

\subsection{El amado en Qumrán}

En los siguientes apartados presentamos el análisis de los textos de 4Q377 fr.1 recto col. II, 5-12; CD-A col. III, 1-21; 4Q213 fr. 1 (4Q213 4QAramaic Levia ${ }^{\mathrm{a}}$; 4Q491 fr. 1= 4Q427; y 4Q522 fr. 9 col. II., que, no obstante, ha sido encontrados en el asentamiento de Qumrán, proceden de diverso origen; la mayoría de ellos hablan acerca de la tradición del amado del rey, tradición vinculada a grupos marginales posiblemente de origen samaritano o esenio norteño que sostenían una posición crítica hacia el templo y el sacerdocio de Jerusalén. Esta posición crítica se puede apreciar en la autodenominación de Efraim como contraposición a Judá u otros líderes que se asociaban al liderazgo jerosolimitano ${ }^{8}$. A juicio de R. Pietrantonio, los samaritanos se identificaban con el término Efraím «ese vocablo les llegó a pertenecer y los individualizó internamente en Israel» ${ }^{9}$. Esta denominación como p.e. CD col. VII, 1-14 señala que «los fieles vinieron a la región del Norte (del exilio)». También en fuentes samaritanas como esenias encontramos puestas de relieve figuras emblemáticas para las tradiciones del Norte como Efraim, José, su Padre, pero también Josué, Moisés y otros líderes del pueblo. En este contexto de tradiciones norteñas, en la literatura de Qumrán existen diversos textos que mencionan con este atributo a personajes de la historia bíblica, los cuales son mencionados como predilectos, como el Mesías, patriarcas o al Maestro de Justicia al que alude el texto de $4 \mathrm{Q} 491^{\mathrm{c}}$.

8 Cf. R. Pietrantonio, El Mesías Asesinado. El mesias ben Efraim en el evangelio de Juan (Buenos Aires 1981) 57-65.

9 R. Pietrantonio, El Mesías Asesinado, 74. 


\subsection{Algunas consideraciones previas}

Una constatación fundamental para contextualizar nuestra investigación es el desarrollo y características que tuvo la apocalíptica judía en relación con el judaísmo rabínico y oficial ${ }^{10}$. Las convicciones que mueven a los grupos apocalípticos están en relación con el emergente cristianismo del siglo I, el cual tomará múltiples aspectos de este movimiento judío.

En contraste con la teología rabínica que eliminará los rasgos sufrientes del siervo de Dios, durante el período del judaísmo tardío, los movimientos apocalípticos desarrollarán la idea del martirio producto de la experiencia de la persecución religiosa. Para este desarrollo teológico se echa mano de figuras emblemáticas como Moisés (4Q377), José (Gn $37-$ 50) o de Elías (ver 2Re 2, 4-5). El tema del sacrificio de José y del rapto de Elías al cielo y la suerte de los demás profetas responde al tema del martirio por la Ley, tema que recorre diversos textos de este período ${ }^{11}$ (ver AscMoisés 9, 1-7; Dn 12, 3; AscIs 2, 33-36). Igualmente en el texto de AscMoisés, Taxo muere pero espera la retribución por su fidelidad a la Ley. Lo mismo que Elías es perseguido, habita en una cueva del desierto y es exaltado al cielo, donde es instituido sacerdote; instruye a sus hijos a seguir fieles a la Ley y a dar testimonio de su fe del mismo modo que $2 \mathrm{Mac}$ 7; la identificación de Taxo con Elías como lo señala F. Hahn y J. Tromp ${ }^{12}$ es antigua. La razón por la cual Elías es arrebatado a los cielos no aparece en 2Re 2, 4-5 sino que corresponde a una relectura que se hace de Elías durante este período, como lo refleja el texto de 1 Mac 2, 58: «Por su celo

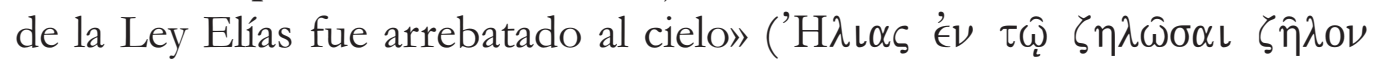

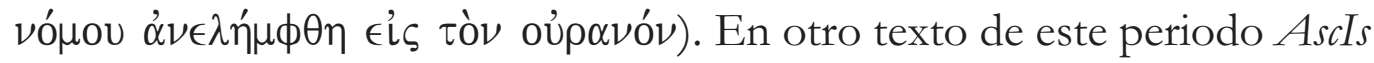
2,33-36, texto probablemente de origen esenio, encontramos un esquema similar, el profeta Isaías en éxtasis está con su Señor en el cielo pero se le

10 «Los Cánticos del sacrificio sabático. Aproximaciones al estudio de la mística judía», Veritas, Vol. IV (2009) 20, 155-167. Especialmente 158.

11 Cf. J. Tromp, The Assumption of Moses. A critical Edition with Commentary (Leiden-New York 1993), 119. Señala el autor que el escrito "rechaza la validación del templo" pero no pertenece a un movimiento esenio; L. HartMan, Prophecy Interpreted. The Formation of some Jewish Apocalyptic texts and of the Eschatological Discourse Mark 13 par (Upsalla 1966) 42-43.

12 Cf. F. Hahn, Christologische Hoheitstitel (Göttingen $\left.{ }^{5} 1995\right)$, 355-356; J. TROMP, The Assumption of Moses, 126-127; T. HARTWIG, «Entwicklungen innerhalb der johanneischen Theologie und Kirche im Spiegel von Joh 21 und Lieblingsjünger texte des Evangeliums», 259-299, im L' Evangile de Jean. Sources, redaction, Thèologie, ed. Marinus de Jonge, (Leuven 1977). 
muestra que debe morir: «Es necesario cumplir tu vida temporal en la corruptibilidad del mundo», la prognosis está en función de la necesidad del martirio, su corona y su trono están preparados por eso debe sufrir el martirio; Isaías, lo mismo que a Elías se le ordena volver para dar testimonio con su muerte. El texto de AscIs 2, 33-36 como el de 1 Mac 2, 58 pretende dar razón de la necesidad del martirio; con perspectivas distintas aportan por una parte la idea de una exaltación en los cielos, y por otra, la necesidad y sentido del martirio. Todo esto nos hace pensar que durante el período anterior a la era cristiana existieron tradiciones apocalípticas que consideraron a Elías, Moisés u otros profetas que han padecido y han ascendido o son exaltados al modo de los ángeles.

\subsection{El texto de 4 Q 377 fr. 1 recto col. II, 5-12}

Las referencias encontradas en Qumrán acerca de Moisés como amigo de Dios puede verse en el texto de 4Q377 fr.1 recto col. II, 5-12, en donde se menciona a éste como un ángel y un mensajero que habita en la nube ${ }^{13}$. En este importante texto se vincula la terminología de mesías, ángel, evangelizador, Moisés y amado. Moisés en el v. 5 de este texto Moisés es su mesías (מושה משיחו); en el v. 10 es «el hombre de Dios» (מיש האלוהים); «ángel» (מלאך) y «heraldo» (מבשר), que convive en la intimidad de la nube y que se traduce en una comunión en la misión, señala este texto: «Él habló como un ángel por su boca». Moisés convive con los ángeles en presencia de Dios y representa a éste ante los hombres, sus palabras son las palabras de Dios. En el texto de 4Q377, no es mencionada la expresión amado, pero es importante notar que es una relectura del texto de Ex 33, 11, en donde se menciona este apelativo referido a Moisés: «Y hablaba Yahvéh a Moisés cara a cara, como uno habla con su propio amigo». El relato presenta a Moisés no tan sólo como un compañero de Yahvéh, sino que ahora es «su Mesías». Este cambio es notable de cara al estudio de los textos joánicos pues es importante recordar que la figura de un Moisés celeste está vinculada a la cuestión del profeta escatológico que es esperado de acuerdo con el texto de Dt 18,15. Es interesante colocar este texto en relación con el de $1 \mathrm{QH}^{\mathrm{a}}$ col. XXIII fr. 1, donde se menciona al heraldo de Is 61, 1s, el cual el mismo Maestro de Justicia se identifica con esta función: «...un heraldo (מבשר) de tu bondad, para proclamar a los pobres la abundancia de tu compasión, ...de una fuente...a los de espíritu quebrantado, y a los que están de duelo eterna alegría». Esto muestra que 4Q377 está en relación

13 Cf. Jan.-Bühner, A., Der Gesandte und sein Weg im 4 Evangelium (Tübingen 1977) 427. 
con la figura del profeta escatológico isaiano. Así, como refleja que hubo una reflexión en torno al amado de Yahvéh, que lo sitúa en el ámbito de la figura del evangelizador que anuncia buenas noticias.

En este contexto, las tradiciones ligadas a Ex 2,1; 6, 16, se reconocía la pertenencia del mismo Moisés a la tribu de Leví; es muy significativo que en la literatura encontrada en Qumrán se subrayan, una y otra vez, estas tradiciones haciendo remontar su genealogía a Leví a través de Amrán, hijo de Qahat, hijo de Leví (ver 4Q543 Visión de Amramª ar) señalando que desde la formación del pueblo en el desierto, éste realizó una función de mediación ante Yahvéh por su pueblo. En esta misma perspectiva no es raro que en otro texto, 4Q545 fr.3, posiblemente se refiere a Moisés cuando dice v. 6 «Él será elegido como sacerdote eterno». Sorprendente, se trata de un mesías celeste profético vinculado a tradiciones norteñas, en el otro, de un mesías davídico, vinculado a tradiciones sureñas. Es significativo que tanto para el Mesías de Israel como para una figura celeste como Moisés se utilice este apelativo, lo cual da indicios de que el tema del doble mesianismo está en relación del «dual leadership» ${ }^{14}$ que florece en el siglo II a.C., y expresa que una figura carismática proveniente de las tribus del Norte participa, en representación de Yahvéh, en los acontecimientos escatológicos.

\subsection{El texto de CD-A col.III, 1-21 (=4Q269, 2)}

El relato dice así: «Abraham no caminó en esto, y fue contado como un amigo por mantener los preceptos de Dios y no siguió el deseo de su espíritu. Y él pasó esto a Isaac, a Jacob y ellos se mantuvieron y fueron contados como amados/amigos de Dios (אוחבים לאל) y como miembros del pacto por siempre». El relato establece un contraste entre los vigilantes y los amigos de Dios. El documento de Damasco coloca de relieve un aspecto del mito de los vigilantes tal como se encuentra en el libro de 1 Enoch. De acuerdo con esto, es clara la vinculación entre ambos movimientos, no obstante que también muestra sus diferencias. Es notable que en este texto, el mito de los Vigilantes sea considerado anti-tipo de la historia de Abraham. La historia del patriarca es leída como contra-ideología del mito apocalíptico. Este relato pretende confrontar la figura de los vigilantes con Abraham, a diferencia del patriarca, aquellos endurecieron su corazón, realizaron sus deseos y faltaron a los preceptos del creador. En cambio, Abra-

14 Cf. J.J. Collins, The Scepter and the Star. The Messiabs of the Dead Sea Scrolls and the Other Ancient Literature (New York-London 1995) 94. 
ham en cuanto amado de Yabvéh, a diferencia de la actitud de los vigilantes, no endureció su corazón, más bien obedeció los mandatos, no siguió el deseo sexual y a consecuencia de esto fue considerado un amigo de Dios (v. 2). Si bien el mito ha sido historizado, la interpretación del pecado de los orígenes está considerada en la perspectiva del endurecimiento de su deseo propio de algunas corrientes de este período. El relato menciona que de la misma manera Isaac y Jacob fueron contados como amigos de Dios y miembros del pacto por siempre. Esta estructura contra-ideológica la volveremos a encontrar en el evangelio joánico (ver Jn 12, 37-41). Tenemos que preguntarnos en este texto, lo mismo que en el siguiente, ¿qué significa que personajes vinculados a tradiciones norteñas sean los beneficiarios de este apelativo? y ¿qué significado se atribuyó a éste? En este texto el tema de la predilección establece una relación con el tema de la gratuidad de la bendición y por consiguiente expresa un paradigma de sucesión carismático, es decir, que conlleva una extensión en el tiempo de la bendición, de tal manera que tanto Isaac como Jacob son amigos de Dios.

\subsection{El texto de 4Q213 fr.1 col. I (CTLevi ar 1Q21)}

El Aramaic Leví corresponde a ocho o nueve fragmentos pertenecientes a una obra perdida llamada con este nombre y que algunos creen corresponde a la encontrada en Qumrán. ${ }^{15}$ Probablemente estos fragmentos pertenecen a un texto que no pertenece a la comunidad de Qumrán, posterior a la crisis Macabea. Por otra parte, habría que diferenciar entre el Aramaic Levi existente en Qumrán del Testamento de Levi Griego perteneciente al Testamento de los Doce Patriarcas ${ }^{16}$. Además, R. Kuggler tomando la hipótesis de J. Milik y considerando los nombres de lugares y la prominencia de Leví y José, señala el origen samaritano de esta obra ${ }^{17}$. Más allá

15 (1Q21, 1QTLevi ar; 4Q213 (4QLevia ar) 4QAramaic Levia; 4Q213a (4QLevi ${ }^{\mathrm{b}}$ ar), 4QAramaic Levi ${ }^{\mathrm{b}}$; 4Q213b (4QLevic ar); 4QAramaic Levic; 4Q214 (4QLevi ${ }^{\mathrm{d}}$ ar) 4QAramaic Levid; 4Q214a (4QLevi ${ }^{\mathrm{e}}$ ar) 4QAramaic Levie; 4Q214b (4QLevi ${ }^{\mathrm{f}}$ ar) 4QAramaic Levi'; 4Q540 (4Qapocryphon of Levia); 4Q541 (4Qapocryphon of Levib? ar).

16 R. A. Kugler, From Patriarch to Priest. The Levi-Priestly Tradition from Aramaic to Testament of Levi (Atlanta Georgia 1996) ; M.E. STONE, «Enoch, Aramaic Levi and Sectarian Origins», JSJ XIX(1988)2, 159-170. Stone data este documento en el siglo III a.C. estableciendo una relación entre el movimiento enoquico y el que representa el testamento de Leví.

17 R A. Kugler, From Patriarch to Priest, 134. No obstante señala: «Quizás los sacerdotes responsables por este trabajo deben estar en el fundamento histórico para un 
de estas cuestiones parece cierto que este texto representa una antigua tradición que coloca las funciones sacerdotales de Leví de modo similar a como las encontramos en Enoch en el libro del mismo nombre, las cuales muestran el liderazgo de Leví sin relación a Jerusalén ${ }^{18}$. La intención de su autor está interesada en una polémica contra alguna forma de sacerdocio, y en la promoción de su particular noción del propio oficio. ${ }^{19}$

En el fragmento 4Q213 (4QAramaic Leviª) fr. 1col. I, 1-5 «...2 en el año ciento dieciocho de mi vida, el año que mi hermano José murió3 yo reunía a mis hijos y sus hijos y comencé a instruirlos 4 de lo que había en mi corazón. Yo comencé hablando y dije a mis hijos: 5 'escuchad la palabra de Leví, tu padre y atiende a los preceptos del amado de Dios' (אל ידיד)».Tanto José como Leví son amados de Dios (ver Gn 37, 2), ambos enseñan la sabiduría o son caracterizados por el amor a ella. En ambos casos se menciona la idea de una túnica especial semejante a la utilizada por los sumos sacerdotes y representan el paradigma del justo. Estas correspondencias no son casuales y alcanzan a la idea de relacionar a Leví como visionario y mesías sacerdotal.

En el texto de 4Q213a (4QAramaic Levi') fr. 1 col. II, 15 «y yo vi visiones...y en la apariencia de visión y vi los cielos abiertos y vi una montaña debajo de mi, alta que alcanzaba los cielos...para mí las puertas del cielos y un ángel me dijo: entra Leví...». En el texto encontrado en Qumrán señala en el v. 5 «escuchad la palabra de Leví, tu padre y atiende a los preceptos del amado de Dios (ידוד אל)». El relato es un discurso de despedida, similar al encontrado en el evangelio joánico, donde el patriarca Leví, al igual que José, su hermano, enseña el camino de la sabiduría a sus sucesores «el que enseña la sabiduría será honrado» (ver Gn 28,17). El tema apocalíptico de los cielos abiertos que encontramos en los evangelios pertenece a esta matriz ideológica (ver Mc 1,11; Hch 7,1) y muestra que el acceso

sacerdocio samaritano, uno explícitamente diferenciado del liderazgo sacerdotal en Jerusalén», no obstante estas indicaciones el autor señala prudentemente que «es sólo una posibilidad»; M. E. STONE, Enoch, Aramaic Levi,168-170; G. BROOKE, «4QTestament of Levid (?) and the Messianic Servant High Priest», 83-100, en Martinus C. de Boer, From Jesus to John. Essays on Jesus and New Testament Christology in Honour of Marinus de Jonge,Sheffield (Sheffield,1993); J.C.Greenfield; M. Stone, «Remark on the Aramaic Testament of Leví from the Geniza (Planches XIII-XIV)», ReB (1979) 2,214-229.

18 J. J. Collins, The Scepter and the Star, 86.

19 Cf. R. A., Kugler, From Patriarch to Priest, 136. 
al mundo divino es revelado a un personaje carismático. Esta apertura de los cielos y las visiones sitúan a Leví junto a los grandes videntes y mediadores del pueblo de Dios, así como José, Daniel y los profetas visionarios de la apocalíptica judía.

En otro fragmento, 4Q213b 4QAramaic Levic, el patriarca luego de un sueño, recibe una visión, en el v. 6 se menciona que Leví es constituido mesías sacerdote-eterno ${ }^{20}$ de la misma manera que es Melquisedec: «Yo he llegado a ser sacerdote eterno para Dios», esta expresión muestra que Leví de modo similar a Melquisedec, ha llegado a ser un ungido sacerdotal celeste. Este modelo ascensional, es decir, el llegar a ser un ungido sacerdotal, expresa la transformación o exaltación de un hombre en un ser celeste. Si consideramos que el documento Aramaic Levi es anterior a los documentos encontrados en Qumrán, tenemos aquí un primitivo testimonio de una «desafección con el corriente sumo sacerdote y la operación del culto del templo» ${ }^{21}$, se trata de una tradición posiblemente norteña en donde el sumo sacerdocio jerosolimitano y el templo son considerados como profanados $^{22}$ de modo similar a como lo encontramos en Hch 3,22; 7,37.48 y Jn 2,13-22 y 4,4-54. Este último aspecto, el tema que Leví ve abiertos los cielos y es investido con las vestimentas del sacerdocio celeste señala a juicio de M. Himmelfarb el esquema de trasformación que posee este texto «lo que es más significativo para nuestro objetivo aquí hay una cosa que el Testamento y el documento arameo tienen en común. En ambos el ascenso a los cielos es seguido por un proceso de consagración como sacerdote en el cual él es ungido y vestido con vestimentas sacerdotales» ${ }^{23} \ldots$ y continúa: "Como el Testamento de Leví deja en claro, hay una dimensión celestial al rol sacerdotal de Leví: "Porque tú estarás cerca del Señor y serás su ministro y declararás sus misterios a los hombres" $(2,10) »$.

Pero además la figura de Leví es importante para nuestro objetivo en relación con su destino martirial. El texto de 4Q541 (4QapocrLevib? Ar) (4QTLevid) datado sobre el 100 a.C., que describe un Leví escatológico que es enviado por Dios con alusiones a la figura de isaiana del siervo

20 Cf. R. Pietrantonio, El Mesías Asesinado, 123.

21 J. J. Collins, The Scepter and the Star, 95; A.J.B. Higgins, «The Priestly Messiah», NTS 13, (1966-67), 211-239.

22 C. Newsom, Songs of the Sabbath Sacrifice. A critical edition (Atlanta 1985), 69.71; J.J. CoLLINS, The Scepter and the Star, 84.

23 M. Himmelfarb, Ascent to Heaven in Jewish and Christian Apocalypses (Oxford 1993), 37. 
de Dios. Algunos autores como E. Puech y Brooke han comparado este texto con TLevi 18 señalando este último «the parallels with T. Levi 18 are almost self-evident», y encuentra referencias de este texto con la figura del siervo de Yahvéh isaiano. Así, p.e., en fr. 2 col. II «tú tomarás las heridas...»; también en el fr. 4 col. II v.2 «el hijo de José...esto sufriendo por...4 tu sangre [...] llevó tus penas (מכאוביכה)». Estos autores hacen notar que este término aparece en Is 53, 3. 4, lo cual indicaría una dependencia de este texto bíblico. También en relación con la construcción de un santuario, el texto de 4Q540 fr. 1 v. 4-5 menciona que «él dejará la casa donde nació y habitará en otra...sirviendo...un santuario [...] el consagrará...».

A juicio de G. Brooke puede ser una alusión a la reconstrucción del santuario que menciona TLevi 18. En otro texto, ya no perteneciente a la literatura de Qumrán el targum de Isaías 53, 4 muestra esta misma interpretación que caracteriza al sufriente del siervo de Yahvéh con la construcción de un santuario, así vemos en la siguiente glosa: «Y él construirá el santuario de Dios que fue profanado». El texto muestra referencias tomadas posiblemente del texto isaiano y que describe a un sumo sacerdote que ha padecido. No es improbable, a la luz del texto de Dn 9, 26 que relata el asesinato del ungido Onias, que este hecho y la profanación del templo fuesen interpretados a la luz del texto isaiano. El contexto de reconstrucción de un santuario escatológico es importante ya que muestra que en el siglo II a.C. se comenzó a interpretar la crisis macabea a la luz de Is 53.

Concluye G. Brooke, que este fragmento habla de «un sacerdote, posiblemente el sumo sacerdote escatológico» ${ }^{24}$. Además es notable en este fragmento encontrado en Qumrán la mención de un mesías hijo de José, esta figura la volvemos a encontrar en el TBenjamin 3, 6-8 «en ti se cumplirá la profecía del cielo que dice que el intachable será contaminado por hombres sin ley, y que el sin pecado morirá por hombres impíos», también en la literatura rabínica (ver Sukkah 52b), a propósito del texto de Zac 12, 12.

En el fragmento 9 col. I de 4Q541 (4QapocrLevib? Ar) (4QTLevid) se puede leer que algunas de sus funciones son la purificación del pueblo, v. 2 «él purificará a todos los hijos de esta generación» y la enseñanza v.3. «su palabra es como la palabra de los cielos y su enseñanza de acuerdo a la voluntad de Dios» fr. 9 col.1, 2 También en los vv. 5-7 de este fragmento

${ }^{24}$ G. Brooke, 4QTestament of Levi (?) and the Messianic Servant High Priest, 89. 
se describen los sufrimientos de este sumo sacerdote con palabras que recuerdan 4Q491' , y el texto isaiano ${ }^{25}$ : «Ellos emplearán muchas palabras contra él, y una abundancia de mentiras; ellos construirán fábulas contra él y usarán todo tipo de acusaciones contra él...7 el pueblo se dispersará en sus días», y también en el fr. 24 col. II, 1 «no llorarán por él», que recuerda el pasaje isaiano. Esto no es casual, los Hoyadot muestran claramente la existencia de una teología del martirio aplicado a líder de la comunidad.

Una cuestión que plantea este texto, es si presenta de hecho una posición contraria o alternativa al sumo sacerdocio realizado en el templo de Jerusalén. Diversos autores han estudiado la postura de los varios movimientos ante el templo de Jerusalén ${ }^{26}$. Posiblemente estamos ante una prueba de que, en tradiciones anteriores a Qumrán ligadas a sectores de levitas o grupos norteños, se vieron a sí mismos como un sacerdocio alternativo, vinculando su sacerdocio a las figuras de Leví y José; en el caso de Qumrán, en referencia a los textos de 4QFlorilegium I, I 2.7; 11Q18 fr. 13 4, concluyen estos autores, que en la comunidad de Qumrán se comprendió la comunidad como templo; para C. Newsom, en relación con la idea reiterada de que una liturgia celestial, con sacerdotes y templo implicaba una deslegitimación del templo de Jerusalén, señala que no se trata de una posición teórica sino una experiencial validation ${ }^{27}$, en cambio, para otros autores como J. Klawars se trata sencillamente de un rechazo del templo ${ }^{28}$.

\subsection{El texto de $4 Q^{491^{c}}$ fr. 1 (4Q427 fr.7; 4Q522 fr. 9 col. II)}

El texto de los Hoyadot pertenece a la literatura de Qumrán, probablemente escrito por el mismo Maestro de Justicia. Dentro de esta colección de Himnos $\left(1 \mathrm{QH}^{\mathrm{a}}\right)$ es preciso integrar el texto de $4 \mathrm{Q} 491^{\mathrm{c}}$ en donde el narrador habla en primera persona señalando que Dios ha dado a él tanto su espíritu como sufrimientos (Col. XX, 12; col.IV, 26; 4Q427 fr.2, 12). En un pasaje que recuerda las confesiones de Jeremías, se lee: «tú me has puesto como un reproche y burla de los traidores...he llegado a ser el

25 Cf. G. Brooke, 4QTestament of Levi (?) and the Messianic Servant High Priest, 96; M. DE Jonge (ed.), Studies of the testaments of the Twelve Patriarchas, (Leiden 1975) 202-210.

26 G. THeissen, O movimento de Jesus. História social de uma revolução de valores (São Paulo 2008) 247.277; F. Schmid, O Pensamento do Templo. De Jerusalém a Qumran. Edicioes Loyola (São Paulo 1994) 126-133.

27 C. Newsom, Songs of the Sabbath Sacrifice, 72.

28 J. KLAwars, Purity; Sacrifice and The Temple. Symbolism and Supersessionism in the Study of Ancient Judaism, (Oxford 2006), 128-129. 
objetivo de calumnias de los labios de los hombres violentos, motivo de burla de sus dientes y he llegado a ser el hazmerreir para de los impíos y la asamblea de los malvados está levantada contra mí» (Col. X, 10-12;3233); más adelante en Col. XIII señala 20-39 representa una larga letanía de dolores «agonía y penas me rodean». Es importante subrayar que tanto el don del espíritu divino como el destino de sufrimientos que acompaña al servidor se remontan a la tradición profética de Is 42,1; 61,1.

Pero también en estos Himnos encontramos como contraste la autoconsideración del salmista como habitando en medio de la «asamblea de los santos»1QHa col. XXVI v.1 «[amigo del rey], mi compañía está con los santos (ידיד מלך רע לקדושים),...con los dioses esta mi posición 8 y mi gloria está con los hijos del rey», y en el v.9 «cantad predilectos, cantad al rey de la gloria...»; este texto tiene su paralelo en 4Q427 [yo soy el amigo del rey, compañía de los santos] el cual está vinculado al texto de 4Q491', por otra parte, el uso de la exhortación cantad, exaltad, santificad de los versículos 13.15. 16 refuerzan la conclusión de que este texto pertenece al mismo cuerpo de Hoyadot.

El texto de 4Q491' dice: «Ha hecho sorprendentes cosas, maravillosamente...2...en la fuerza de su poder los justos exultarán, y los santos se regocijarán en...en justicia3...ha establecido a Israel desde la eternidad; su verdad y los misterios de su sabiduría en todas las generaciones...poder4... y en el concilio de los pobres para una congregación eterna...los perfectos de5...eterna; un poderoso trono en la congregación de los dioses arriba del cual ninguno de los reyes del Este se sentarán, y sus príncipes...asemejan 6...mi gloria es incomparable (כבודו לוא ידמה) y excepto yo ninguno es exaltado (ירומם), ni viene a mí, porque yo habito en..., en los cielos, y allí no hay...7 ...yo soy contado entre los dioses y mi morada está en la sagrada congregación; mi deseo no es de acuerdo a la carne, pero todo lo que es precioso para mí está en la gloria (בכבוד) de8...la sagrada morada. ¿Quién ha sido considerado sobre mi cuenta? Y ¿quién es comparable a mi gloria? ¿Quién como el marino vuelve y cuenta? ¿Quién lleva todos los sufrimientos como yo? (מיא שיא כול צערים כמוני) ¿Y quién sufre (יסבול) el mal como yo? No hay ninguno. Yo he sido instruido, y no hay enseñanza comparable (תדמה) 10 a mi enseñanza...y ¿Quién me atacará cuando abro yo mi boca? Y ¿Quién puede aguantar el fluir de mis labios? y ¿quién puede enfrentarse conmigo y frenar la comparación de mis juicios? 11... amigo del rey (ידיד מלך רע לקדושים), compañía de los santos... incomparable entre los dioses es mi posición y mi gloria es con los hijos de los 
reyes. Para mí pertenece el oro y para mí el oro de ofir12...13...exultad justos, en el Dios de...en las santas moradas, cantad para él...14proclamad durante la meditación...en eterna alegría; y no hay...15...para establecer el cuerno de su mesías...16...para hacer saber su poder con fuerza...17».

Este relato está caracterizado por el uso de la primera persona, que recuerda el estilo de los discursos joánicos. Esto se realiza tanto por el uso del pronombre personal yo vv. 6(2).11, como por el uso del pronombre posesivo mi vv. 6. (4). $7(3) .8$ (3). 9 (2). 10 (4). 11 (2). 12. El pronombre interrogativo (מיא) se repite siete veces como factor de comparación entre la posición del protagonista y sus hipotéticos oponentes, pues es posible que también esté en relación con Enoch (1 Enoch 93,11): «Qué hombre puede considerar todas las obras de los cielos o la columna angular sobre la que descansa o quién puede ver un alma o espíritu y volver a contarlo, o subir y ver la comunidad completa y pensar y actuar como ellos?». Es importante señalar que el estilo que asume el relato no es en retrospectiva como Is 52-53, sino que es relatado por el mismo protagonista de los hechos, en primera persona $y$, o los sufijos de primera persona, con los cuales el narrador se autoglorifica: v. 6. «mi gloria es incomparable», «A mi lado nadie es exaltado», «...porque yo habito en los cielos»; en el v. 7 «yo estoy contado entre los dioses para aconsejar y mi residencia está en la asamblea de los santos» y en el v. 11 «...incomparable, porque entre los dioses está mi posición».

En cuanto al estilo, es importante hacer notar en primer lugar, que recuerda el estilo de los salmos, y segundo, el uso profético del pronombre personal en el déutero-Isaías que remite las expresiones en primera persona del cuarto evangelio. Es todavía más importante si nos percatamos de que, en la literatura religiosa, el uso del pronombre personal de primera persona es reservado sólo a la divinidad o a personajes elegidos como profetas y justos que están vinculado a Dios de un modo eminente. Segundo, la comparación del marino v.8 se encuentra en 1QH ${ }^{a}$ col. XIV, 22: «Yo he llegado a ser como un marino en medio del mar tempestuoso», demuestra la dependencia de este texto de los Hoyadot. La imagen responde a la del sabio que es comparado con el marino sobreviviente de la tempestad que puede contar lo que ha vivido (ver col. XI, 14; col. XIV, 22: los hombres sabios son como marinos). Tercero, además, la asociación de su estatuto al sufrimiento y a la instrucción (vv.8-9), hacen pensar que este personaje sea un ser humano y no un ángel. El texto dice: «¿quién puede llevar todos los sufrimientos cómo yo? Y ¿quién puede sufrir el mal como yo? No hay ninguno». Esta referencia a la pasión de este servidor es fundamental 
porque guarda relación con los sufrimientos que padece el Maestro de Justicia encontrados en otros lugares de los Himnos y por consiguiente vincula el tema de la exaltación y glorificación del personaje con los sufrimientos y persecución que ha padecido. Cuarto, en este mismo contexto es importante añadir el uso de algunos salmos como ya ha sido mencionado, en los Himnos encontramos la cita de los salmos 22, 2; 42,6 y 69 (ver 1QHa 20,23-24), los cuales también encontraremos empleados en los relatos evangélicos de la pasión. Esto muestra que estos salmos pertenecen a una tradición relativa al martirio del justo presente en círculos judíos en el tiempo pre-cristiano. Además, los contactos con el texto de

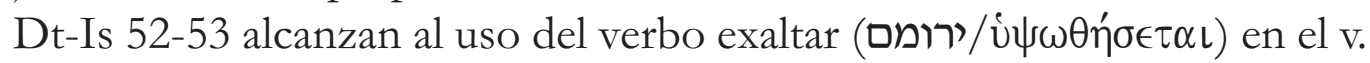
6 y en la mención de la gloria (כבודו) en los vv.6.8.11, además, la mención de los reyes que recuerda Is 52, 15 «Los reyes cerrarán la boca delante de él, porque verán lo que nunca les había sido contado, y comprenderán lo que nunca habían oído». Además, la expresión del v.8 «¿Quién lleva todos los sufrimientos como yo? (מיא שיא כול צערים כמוני) ¿Y quién lleva los dolores como yo?, ¿quién (מיא) sufre el mal como yo? No hay ninguno», recuerda a Is 53, 4: «Ciertamente él llevó nuestras enfermedades y sufrió nuestros dolores» (אכן הלינו הוא נשא ומכאינו סכלם). De todos modos, es necesario señalar que falta en estos contactos la perspectiva de retrospectiva de los hechos y la narración en tercera persona tan característica de Is $52-53$ y Sab 2-4.

\subsection{El texto de 4Q522 fr.9 col. II 8 (Prophecy of Joshua)}

Aparte de los anteriores textos mencionados, la denominación del amado la encontraremos utilizada también en 4Q522 fr. 9 col. II 8 donde habla del amado de Yabvéh (ידיד יהוה) para referirse al Mesías, el hijo de Jesé. Dice el texto, 4Q522 fr.9 col. II 8: «Establecerá allí la tienda del encuentro... 3 del tiempo. Porque un hijo de Jesé ha nacido, hijo de Perez, hijo de Judá... 4 la roca de Sión, y él sacará desde allí a todos los amoraitas desde... 5 él construirá la casa de Yahvéh, Dios de Israel. Oro y plata...6él llevará cedro y ciprés desde el Líbano para su construcción, pero su hijo el más joven...7él oficiará allí primero...y para él...8...en todas las residencias de los cielos, porque el amado de Yahvéh (ידיד יהוה) habitará en paz...9los días y su pueblo vivirá por siempre. Pero ahora, los amoraitas están y los cannanitas10 habitantes que han hecho pecar a ellos...12 y ahora, establécenos la tienda del encuentro lejos de...13Eleazar y Joshua la tienda del encuentro desde Bet El...14Joshua...jefe del ejército...». 
El texto habla de Eleazar y Joshua, con la designación del amado de Yahvéh se refiere a Joshua sucesor de Moisés ${ }^{29}$ (Nm 13, 16; Test Moisés 10,15). Moisés acoge a Oseas hijo de Nun, y le cambia el nombre por Joshua, éste es puesto delante del sacerdote Eleazar. Este cambio es notable ya en este texto, la sucesión profética es diferenciada de la sacerdotal claramente; en el texto de 4Q522 establece una relación entre el liderazgo carismático de Moisés y el mesías «hijo de Jesé» (v.2), llamado también en el v. 4 «la roca de Sión» (סלע צחון) que «establecerá la tienda del encuentro» (v. 2), construirá la casa de Yahvéh (v.5), y erradicará a los amoraitas (ver 4Q161). En el v. 8 «...en todas las residencias de los cielos, porque el amado de Yahvéh vivirá en seguridad...y su pueblo vivirá por siempre». En este texto nuevamente encontramos relacionado el tema del amado de Yahvéh con la construcción de un templo. Un modelo semejante lo sigue el texto de 4Q161 (4QIsaiah pesher') 20 que interpreta el pasaje de Is 11, 1-5 que habla del vástago de Jesé para referirse al Mesías de Israel, en ese contexto aunque no habla del amado, si describe al mesías en relación con la exaltación y su función de regir con justicia «trono de Gloria, santa corona y multicolores vestimentas 21 ...su espada juzgará a todos los pueblos. Así como lo que dijo: él no juzgará por apariencias o dará veredicto por oídas, su interpretación».

A pesar del carácter fragmentario del texto, se puede deducir que se habla del trono de la gloria para referirse a uno de los atributos del mesías retoño de David. El vínculo es débil, pero es probable que esta conexión esté en relación con la expresión de Is 42, 1 utilizado en los sinópticos en la persona de Jesús. El texto menciona «las vestimentas» que recuerdan los Cánticos del sacrificio sabático, en donde se describe la gloria de Yahvé en términos de un sacerdocio celeste. M. Himmelfarb señala al respecto: «El cantico del sacrificio sabático sugiere que la comunidad de Qumrán también vio una relación entre las vestiduras sacerdotales y la apariencia de Dios. En el decimotercer y último de las cánticos, los vestidos del angélico sumo sacerdote son descritos en lo que Newsom llama el clímax de los canticos $»^{30}$, para Himmelfarb, «la gloria es descrita en términos asociados con los sacerdotes celestiales» ${ }^{31}$.

\footnotetext{
29 Cf. R. Pietrantonio, El Mesías Asesinado, 270.

30 M. Himmelfarb, Ascent to Heaven, 20.

31 M. Himmelfarb, Ascent to Heaven, 19.
} 


\subsection{Algunos contactos con el discípulo amado joánico}

En nuestro artículo Orígenes de la cristología del cuarto evangelio, hemos señalado varios e importantes motivos que remiten a una matriz común entre la literatura de Qumrán y el cuarto evangelio ${ }^{32}$. Sin querer repetir lo ya dicho, señalamos algunos elementos fundamentales que es necesario considerar.

En nuestro análisis de los textos encontrados en Qumrán acerca del amado de Dios hemos seguido un criterio lingüístico en vista de analizar los diversos aspectos temáticos que contiene esta expresión. Un primer elemento importante es que hemos encontrado que el término Tידי ידsee en 4Q377 fr.1 recto col II, 5-12; 4Q213b 4QAramaic Levic ; 4Q 522 fr.9 col. II 8; 4Q545 fr.3 connotaciones mesiánicas, ligado a tradiciones norteñas. En algunos casos se trata del profeta como Moisés que ha llegado a ser mesías, ángel y evangelizador. Si tomamos en consideración que Moisés es uno de los paradigmas del profeta escatológico, entonces tenemos una prueba de la convicción entre grupos apocalípticos o tradiciones norteñas de un profeta-ungido del mismo modo como se aplica en el cuarto evangelio. En otros textos, se trata de Leví, que ha llegado a ser mesías sacerdotal celeste o como en 4Q522 fr. 9 para referirse al mesías hijo de Jesé. Desde un punto de vista terminológico, el uso del término exaltado (ירומם), glorificado (כבודו), encontrados en 4Q491', así como (מבשר) en 4Q377 expresan un esquema de transformación, el cual muestra no sólo vínculos, sino perspectivas fundamentales de la cristología joánica. Los tres términos pertenecen a la tradición del profeta escatológico isaiano (Is 42,1; 49,1; 52-53; 52,7) y que volveremos a encontrar en el cuarto evangelio.

El texto de 4Q377 coloca en evidencia la relación del amado de Dios con la experiencia de la intimidad con Yahvéh, ésta es descrita como acceso al mundo divino tanto en 4 Q377 como en 4 Q491 ${ }^{\mathrm{c}}$, se señala que Moisés es un ángel y que convive en la presencia de Dios. De modo similar, el Maestro de Justicia señala que convive con los santos. Esta intimidad guarda relación con la que el cuarto evangelio menciona de Jesús y del discípulo amado. Expliquemos esto, el evangelista utiliza el paralelismo temático para explicar la continuidad entre Jesús como enviado y la comunidad; múltiples expresiones del cuarto evangelio hacen referencia a esta característica, sobre todo los textos de Jn 1,18 y 13, 23 deben ser mencionados: «A Dios nadie le ha visto jamás; el unigénito

32 Nota 4. 
que está en el seno del Padre, él le ha dado a conocer». Y el relato de 13, 23 muestra que: «Y uno de sus discípulos, al que Jesús amaba, estaba recostado en el seno de Jesús». Jesús como amado del Padre tiene su correspondencia con el discípulo amado y su comunidad. En el mismo pasaje de Jn 13, 23-25 y en los siguientes pasajes que hablan del discípulo amado, éste tiene funciones ${ }^{33}$ y prerrogativas que otros discípulos no tienen y que recuerdan las características sólo esbozadas en este estudio, como por ejemplo, la de ser el sucesor, preguntar al Maestro por los misterios, la prioridad sobre otros discípulos como Pedro y la de ser el visionario de la comunidad.

Un tercer aspecto fundamental que hemos querido subrayar que muestran los textos de Qumrán es la relación del amado de Yabvéb (ידיד יהוה) con la experiencia del martirio. Los textos de 4QApocrLevi; 4Q541 fr. 9; en los Hoyadot $\left(1 \mathrm{QH}^{\mathrm{a}}\right)$ y 4Q491 ${ }^{\mathrm{c}}$ encontramos concomitante con la experiencia de exaltación (ירומם) y glorificación (כבודו) un cierto ministerio martirial. En este sentido la apropiación de textos del justo que sufre por medio de los salmos 22, 42 y 69 así como textos del profeta Jeremías y del déutero-Isaías como muestran los textos analizados establecen una relación de éstos con la figura del amado en el cuarto evangelio. Esto establece una clave esencial para entender la cristología del Hijo del hombre joánico. Si comparamos estos datos con los que encontramos en el cuarto evangelio acerca de la comunidad joánica, éstos son odiados por el mundo (Jn 17,14); excomulgados de la sinagoga $(9,42.34)$ o se pretende matar a los seguidores $(12,10)$ y se les acusa de blasfemia $(10,33.35 ; 5,18)$. Esto tiene su origen en la hostilidad que rodea al mismo Jesús, así, p.e., lo persiguen $(5,16)$ intentan apedrear (ver 8, 59; 10, 10.31), matarlo (5, 19; 7,1; 11,53); acusado de blasfemar el nombre de Dios (Jn 10, 33.36). ${ }^{34}$ Este contexto de complot y muerte del amado de Yahvéh que encontramos tanto en Qumrán como en el cuarto evangelio se explica por una teología del martirio subyacente existente en círculos apocalípticos, sobre la cual se ha desarrollado el relato de la pasión joánico. No es casualidad que a partir del capítulo 13, en el contexto de un discurso de despedida, similar al encontrado en 4Q213a, el evangelista introduce la figura del discípulo que Jesús amaba. Pero además ante la idea tan difundida de que el uso ưนów es cristiano, este estudio sugiere como hipótesis que se debe inves-

\footnotetext{
33 El discipulo amado, 429-434.

34 B. Lindars, Behind the Fourth Gospel, SPCK, (London 1971), 70.
} 
tigar que la cristología del Hijo del hombre joánico debe integrar simultáneamente tanto el martirio como la exaltación.

\subsection{Algunas conclusiones}

La figura del amado es un tema central en la cristología del envío en el cuarto evangelio. Tanto el Hijo del hombre como el discípulo amado responden a este paradigma. Como ha sido desarrollado en este artículo, el tema del amado del rey representa una categoría sociológica existente en las monarquías del Medio Oriente del pre-exilio, el cual es utilizado a la vuelta del destierro por corrientes apocalípticas para comprender el mundo celeste, Dios también tiene amigos, amados, con los cuales reina, comparte y delibera, a éstos elige y entrega funciones escatológicas. La presentación y análisis de los textos expuestos comprueban el origen apocalíptico de esta expresión y con ello, primer aspecto de nuestra primera hipótesis. Los grupos apocalípticos del judaísmo tardío reflexionaron acerca del amado en relación con el estatuto profético de seres humano-divinos como Abraham, Moisés, Leví o el mismo Maestro de Justicia. Ellos son considerados amigos de Dios ya por su actitud obediente, o por su fidelidad a los mandamientos. Esta amistad está vinculada a la misión encomendada y no se comprende como una predestinación, ellos son mediadores y llevan a cabo el plan salvífico de Yahvéh en la historia.

Un segundo elemento de nuestra hipótesis es la convivencia entre esta expectativa del amado de Dios con elementos supuestamente pertenecientes a distintos estratos en la cristología joánica, específicamente la idea de una exaltación y el destino martirial del amado de Yahvéh. En textos de origen pre-qumrámico, posiblemente vinculados a grupos norteños o samaritanos como el texto de 4Q213 fr.1 col. I (CTLevi ar 1Q21), indicamos la importancia que tiene la relación de Leví con José, ambos son amados de Dios y ambos buscan la sabiduría, ambos reciben una túnica y en el caso de Leví es constituido sacerdote eterno; además, a su función le es inherente un ministerio de sufrimiento, así en el fragmento de 4Q541 (4QapocrLevi ${ }^{\text {b? }}$ Ar) (4QTLevi ${ }^{\circledR}$ ), en el fr. 4 col. II v.2 habla de «el hijo de José...esto sufriendo por...4 tu sangre [...] llevó tus penas (מכאוביכה)». En diversos textos la figura de José es repetida, esto es muy significativo, pues la figura de José representa un paradigma de una teología del martirio. Estos elementos nos indican que se trata de un modelo profético ascendente, en donde el amado llega a ser, esto es se transforma en sumo sacerdote 
celeste, exaltado o Mesías ${ }^{35}$ a través de la pasión. En este texto se muestra que el tema del amado del rey está en relación tanto con ser receptor de visiones divinas, asumir un sacerdocio celeste o, como es el caso de 4Q491' con una exaltación de este sujeto en los cielos unido a la convicción de su servicio a través del sufrimiento. En otros textos, la figura del mesías sacerdotal desarrolla la idea del sufrimiento que conlleva este estatuto. Pareciera ser que durante este período se comienza a utilizar la terminología del texto de Is 52-53 (ירומם) y (כבודו) para aplicarlo al pueblo perseguido y martirizado bajo la dominación helénica y luego romana. Además, se aplica a determinados personajes como el Maestro de Justicia con funciones proféticas y sacerdotales del siervo de Yahvéh. ${ }^{36}$ Éste tiene las funciones de purificar al pueblo y entregar sabiduría y adoctrinar al pueblo. A su vez, la exaltación expresa tanto el destino de sufrimiento que conlleva como la autoglorificación que describe el relator del texto, subrayando con esto el incomparable honor que le ha tocado. Es importante notar que la designación está referida a seres humanos que han experimentado una transformación o una elevación de funciones en cuanto un hombre puede llegar a ser mesías de Israel y o seres semi-divinos como Moisés o Leví, o como el que habla en el texto 4Q491 fr. 1 (4Q427; 4Q522 fr. 9 col. II; 4Q213 fr.1 col. I (CTLevi ar 1Q21). Además, en algunos de los textos hemos comprobado la vinculación del sufrimiento del amado del rey unido a su destino final de exaltación, lo cual establece un antecedente importantísimo para la reflexión de la cristología joánica.

En todos estos relatos se pone en evidencia un dato fundamental: existió una teología del martirio pre-cristiana unida a la idea a la exaltación en los cielos así como la que encontramos en los relatos de la pasión sinópticos y joánico. Estos resultados debieran llevar a reformular la idea presente en algunos comentarios ${ }^{37}$ acerca de la necesidad de diferenciar estratos o fases en la cristología joánica. Según éstos, los textos referidos al discípulo amado en el cuarto evangelio representan una fase posterior de un redactor eclesiástico, pero hemos podido demostrar en los textos qumrámicos, con relación al amado de Dios, su origen apocalíptico, la unión entre la idea del sufrimiento y exaltación, así como el carácter profético de estos personajes. Por consiguiente se puede constatar como

35 M. Himmelfarb, Ascent to Heaven, 30

36 (4Q541 (4QapocrLevib? Ar) (4QTLevi ${ }^{\mathrm{d}}$ ) 4Q491c fr. 1 (4Q427 fr.7; 4Q522 fr. 9 col. II).

37 Ver nota 2 . 
arbitrario el intento de distinguir estratos o reinterpretaciones en base a criterios temáticos.

Finalmente, en el movimiento de Qumrán el tema del amado del rey es una relectura de los patriarcas y profetas pertenecientes al período anterior al destierro, posiblemente vinculado a tradiciones del Norte. Los textos analizados mencionan con este adjetivo amado a un ser humano, tanto si es un patriarca, un profeta como un ser desconocido como es el caso de 4Q491. En relación al tercer punto de nuestra hipótesis, la figura del amado de Dios es una figura profética enviada desde el cielo pues asiste al trono de Yahvéh, por consiguiente, las categorías de profeta y ángel y eventualmente la denominación de mesías son concomitantes como aparece en 4Q377. Tanto el paradigma de este Moisés celeste como la designación de mesías son fundamentales para comprender la cristología joánica, la cual está centrada en el título mesías y no la de profeta. En este texto, que proviene del movimiento esenio de Qumrán, Moisés, como otros visionarios, son relacionados con la tribu de Leví. Tanto en el caso de 4Q377 como en el texto de 4Q213 fr.1 col. I (CTLevi ar 1Q21), los visionarios pertenecen a esta tribu. Este elemento constituye un aspecto significativo, ya que muestra que hubo una corriente vinculada al servicio del templo de Jerusalén, crítica a la práctica cultural realizada. En estos textos, Moisés es un amado de Dios, profeta escatológico y mesías, quien comparte en la nube la intimidad y habla en nombre de Dios a los hombres. Esto demuestra que existió antes de la era cristiana la expectativa de un mesías profeta perteneciente a la tribu de Leví, que ejercería un rol profético vinculado a los ángeles. Notemos que dicha cuestión arroja luz acerca de la tradición presente en el evangelio de Juan acerca de la realización de señales que realiza el mesías. 
Resumen: El artículo estudia la hipótesis sobre una matriz apocalíptica común relativa al tema del amado de Yahvéh existente en textos qumrámicos y la cristología joánica. De acuerdo a esto, avanza en esta relación que es la hipótesis de trabajo, estudiando los textos encontrados en Qumrán: 4Q377 f.1 recto col. II, 5-12; CD-A col. III, 1-21; 4Q213 fr. 1 (4Q213 4QAramaic Levia); 4Q491 fr. 1;(4Q427); y 4Q522 fr. 9 col. II, que hablan acerca de la tradición "del amado del rey", el que representa una tradición vinculada a grupos marginales samaritanos o esenios norteños que formulan un templo y sacerdocio alternativo al del templo de Jerusalén. El artículo coloca en evidencia aspectos que vinculan la figura del "amado del rey" con una teología que contiene tanto el tema de la exaltación, auto-glorificación como una reflexión acerca de los sufrimientos que ha padecido el siervo de Dios. Esta tradición martirial es concomitante con la categoría profética del emisario ya estudiada por J. Ashton, J. Bühner y por nosotros en un artículo reciente, la cual explica y coloca los fundamentos de posteriores estudios comparativos con la cristología del cuarto evangelio.

Palabras clave: Qumrán, cuarto evangelio, exaltación, amado de Dios, cristología.

Abstract. This paper studies the common apocalyptic matrix hypothesis regarding Yahvéh's beloved in the Qumran literature and Johannine Christology. This analysis advances in this direction by studying the texts found in Qumran: 4Q377 f.1 recto col. II, 5-12; CD-A col. III, 1-21; 4Q213 fr. 1 (4Q213 4QAramaic Levia); 4Q491 fr. 1;(4Q427); y 4Q522 fr. 9 col. II, which refer to the tradition of the beloved of King', who represents a tradition linked to marginal Samaritan groups or northern groups that explain an alternative temple and priesthood to that of Jerusalem. The article exposes features that link the 'beloved of King' figure with a theology that includes exaltation, self-glorification and reflections about the suffering that the servant of God withstands. This martyrdom tradition is concomitant with the prophetical category of the emissary studied by J. Ashton and J. Bühner, as well as by us in a recent study that explains and exposes the foundations of later comparative studies with the Christology of the Fourth Gospel.

Keywords: Qumram, Fourth Gospel, exaltation, Yahvéh Beloved, Christology. 